\title{
Estruturas e sistemas no idealismo kantiano
}

\author{
Elisabeth Schwartz \\ Universidade Blaise Pascal - Clermont-Ferrand - França \\ elschwartz@easynet.fr
}

resumo No chama do período do "estruturalis mo" defendeu-se a idéia de que havia uma oposição entre essa filosofia e o idealismo, especialmente o idealismo subjetivo. 0 propósito deste texto é defender a tese oposta, de que há um forte elo interno entre o criticismo kantiano e o método estrutural em história da filosofia.

Esse elo é particularmente visível no estruturalismo e na Dianoemátia de Gueroult e também pode ser ilustrado na obra do grande intérprete da filosofia kantiana que é Louis Guillermit. Este aplicou seu método de "elucidação crítica" à interpretação da sistematicida de de todo o período crítico de Ka nt e especialme nte da constituição pro g ressiva da Estética transcendental nas três Críticas.

A eluc idação da gênese das estruturas perma nece inter na ao sistema kantia no, deixando em aberto a questão da natureza de sua ligação com os sistemas pós-kantianos, mas essa neutralida de é mais apare nte que real, e cons o a nte com a escolha do idealismo kantia no em detrimento do idealismo hegeliano.

palavras-chave Estruturalismo; Dia noemática; elucidação crítica; Martial Gueroult; Louis Guillermit; Idealismo alemão

Não se pode, sem dúvida, tentar articular hoje uma reflexão sobre as relações entre filosofia da subjetividade e filosofia das estruturas no seio dos sistemas sem que se evoque certa fortuna, absolutamente contemporânea, do chamado estruturalismo, cuja viva memória no Brasil e na Universidade de São Paulo, em virtude da herança deixada por autore s como Lévi-Strauss e Michel Foucault, está na origem da escolha do tema

Recebido em 20 de dezembro de 2007. Aceito em 02 de fevereiro de 2008.

Tradução: Márcio Suzuki

doispontos, Curitiba, São Carlos, vol. 5, n. 1, p.11-42, abril, 2008 
proposto para o presente encontro. ${ }^{1}$ E por isso, certamente, a questão extrapola bastante o quadro da mera história da filosofia, na qual, no entanto, o mencionado estruturalismo acreditou poder reconhecer um bem seu, encontrando confirmação de suas idéias-mestras nos escritos de um Martial Guéroult ou de um Victor Goldschmidt, estes últimos também à época tão presentes e tão ligados a este Brasil de que Clermont hoje acolhe os testemunhos.

Se escolho trabalhar o tema que nos reúne estudando a questão do idealismo kantiano, não me proponho a apresentar, em poucos minutos, uma nova interp retação desse idealismo à luz do método das estruturas, método que não se deixa praticar em abstrato, nem violentando rudemente o detalhe dos textos. A questão, aliás, é justamente saber que textos! Meu propósito será antes, e de maneira bem limitada, o de fazer sobressair exatamente aquilo que liga, na filosofia kantiana, a reivindicação de certa forma de idealismo por parte do autor à presença do tema do sistema, tão forte em seu pensamento, como também à presença das estruturas na metodologia que o sistema aplica a si mesmo pelo movimento próprio à sua constituição interna, movimento tal qual, muito precisamente, o historiador estruturalista se propõe a captar. Isso porque é num mesmo movimento e num mesmo gesto que, de um lado, a filosofia transcendental submete, sempre, o conteúdo do pensamento àquilo que lhe condiciona o sentido e que, de outro, o seu leitor pode fazer da estrutura, condição do sentido, ao mesmo tempo o objeto e o resultado esperado de sua explicação do texto, nisso em total conformidade com o propósito de uma filosofia que se definiu como crítica.

Tentaremos, pois, apresentar:

1) o profundo parentesco existente entre filosofia crítica e método das estruturas na constituição e interpretação do sistema kantiano, cuja subjetividade não é, em tais condições, de modo algum o ponto cego que seria preciso sacrificar à estrutura, mas antes, muito precisamente, a condição de sua eficácia constitutiva e explicativa.

2) as precisões essenciais que a questão da sistematicidade do idealismo kantiano recebe deste ponto de vista, idealismo kantiano cuja unidade e arquitetônica estão intimamente ligadas a certa pluralidade e mesmo a certa instabilidade das estruturas em seu interior. Assim, pôdese pedir ao método das estruturas, e evocarei aqui a obra de Louis 
Guillermit, que: a) colocasse numa relação de confirmação recíproca ou de coerência intrínseca os traços de uma sistematicidade interna que o pós-kantismo havia julgado, com Hegel, insuficiente em sua efetividade, ou que ele havia recomendado, com Fichte, que se suplantasse devido a sua reconciliação imperfeita entre um dizer e um fazer teóricos; b) que fizesse sobressair assim, sob o caráter compósito e mesmo obscuramente instável da arquitetônica da Primeira Crítica, a presença de uma unidade orgânica, invariante, do sistema inteiramente constituído.

3) o alcance que é preciso conferir aos recursos que o método das estruturas oferece para a apreciação do sentido da unidade, ou do centro de gravidade, ou do motor da constituição do sistema kantiano em sua totalidade, na medida em que pode ser considerado como um monumento isolado ou auto-suficiente na história do idealismo, ou como um momento do idealismo alemão que ao mesmo tempo abre e fecha a via para os sistemas que, depois dele, disputaram entre si a exclusividade e a efetividade da filosofia subjetiva inaugurada pela revolução copernicana.

$$
* * *
$$

\section{A filosofia das estruturas e o idealismo transcendental}

Se no seu período de surgimento e, posteriormente, de glória, nos anos do pós-guerra na França, aquilo que, sob o nome de "estruturalismo", devia declarar guerra a uma certa forma de filosofia reflexiva, ou idealista, acabou com efeito por abrigar em sua cruzada anti-subjetivista autores e correntes bastante distintos, como o estruturalismo das ciências humanas, o estruturalismo de certa forma de história não fatual, a crítica althusseriana de Marx, o estruturalismo dos matemáticos bourbakistas e mesmo as epistemologias de um G. Canguilhem, mestre de M. Foucault, ou de um Jean Cavaillès, em quem se pretendeu ver inicialmente um destruidor da epistemologia idealista; s e, portanto, durante esse período foi possível cometer confusões tão grosseiras entre diferentes conceitos de "estrutura" postos em jogo, confusões logo denunciadas por um brasileiro de coração, G. G. Granger, no segundo Prefácio de Pensamento Formal e Ciências do Homem (GRANGER, 1967), em que ele chama a atenção do 
leitor para a pluralidade, irredutível segundo ele, das estruturas, é muito claro, hoje, que essas amálgamas não tiveram êxito no combate que pretendiam levar adiante contra um conceito de sujeito identificável unicamente naquela confusão.

O que talvez se note menos freqüentemente é que o método das estruturas, no sentido de Martial Guéroult, buscou sua inspiração mais profunda e mais forte na filosofia transcendental de Kant. Isso foi vigorosamente indicado por Louis Guillermit desde o ano de 1977. ${ }^{2}$ Ele não chama, no entanto, atenção para um traço que nos será necessário comentar, e que será talvez mais acentuado em Jules Vuillemin que em Gueroult, de quem tanto elogia o método e faz frutificar a herança com relação a Descartes, Kant e Fichte: esse traço é a grande reticência, e por vezes mesmo a franca desconfiança, de Gueroult acerca do sistema hegeliano, sistema ao qual o de Kant permite propor, e opor, uma alternativa, ao passo que, como bem havia assinalado o Gueroult da tese sobre a Doutrina-da-Ciência, o sistema de Fichte pode ser entendido como um momento instável do idealismo hegeliano, que esse último ultrapassa e coroa no plano do conteúdo, ao mesmo tempo em que lhe esclarece o desenvolvimento pela crítica interna dele mesmo. ${ }^{3}$ No número dos Arhiv em homenagem ao grande historiador que acabava de desaparecer, Louis Guillermit tampouco se contentava em invocar uma onipresença, mesmo que indireta, do pensamento kantiano em Gueroult. Onipresença na reconstituição minuciosa do contexto histórico da Doutrina-da-ciência e, sobretudo, no restabelecimento cerrado da textualidade e da estrutura do texto da primeira Crítica contra a interpretação hegeliana dos seus "deslocamentos", assim como na defesa da pureza do método crítico contra o dogmatismo fichtiano, que exorbitava, em relação a esse método, em sua pretensão de realizá-lo melhor do que a primeira forma de idealismo subjetivo o havia conseguido. Com efeito, aqui ainda se poderia observar tão-somente uma preferência marcada de Gueroult por Kant sobre o idealismo especulativo, primeiramente saudado e admirado por ele, e depois progressivamente assimilado às obras de uma modernidade irracionalista, saída, segundo ele, do romantismo. Obras que não apenas não foram objeto de um tratamento estrutural da parte de Gueroult, mas também em relação às quais ele viria a reconhecer, no fim de sua vida, que ali ele via tudo, menos filosofia... Contra muitas dessas obras, de 
autores que vão de Schlegel a Nietzsche, obras que o elegeram como alvo, Kant desempenhará agora a função de uma cidadela. ${ }^{4}$

A razão sobre a qual é preciso insistir antes aqui, para uma espécie de parentesco que o método das estruturas do Gueroult historiador tem com o idealismo kantiano, não é sem dúvida nem uma questão de gosto - o Gueroult filósofo preferia o idealismo crítico ao idealismo absoluto -, nem de simples convicção de que haveria um liame interno que vai do kantismo ao pós-kantismo, o segundo não podendo ser compre en dido sem o primeiro mesmo se ele o abandona, enquanto o primeiro pode encontrar sua coerência ignorando e mesmo recusando os convites que seus sucessores e "amigos" faziam para que se desse o passo que levaria a sair dele. Com efeito, a onipresença indireta da inspiração kantiana no método das estruturas pode ser claramente lida na concepção gueroultiana da Dianoemática, que seria publicada postumamente ${ }^{5}$, mas de que, desde 1977, os seus alunos, como Guillermit e Goldschmidt, já podiam evocar os fragmentos inéditos ou as antecipações nos textos publicados. ${ }^{6}$ Ora, essa concepção encontra, segundo L. Guillermit, seu paradigma mais claro na definição da essência crítica da filosofia kantiana. E isso por dois traços particularmente salientes.

Em primeiro lugar, pelo parentesco do conceito de uma estrutura que doa unidade a uma diversidade, sentido a um conteúdo, sistematicidade a um agregado, com os temas principais do capítulo da Arquitetônica da Crítica da Razão Pura. "Sob o governo da razão (Regierung der Vernunft), nossos conhecimentos em geral não poderiam constituir uma rapsódia, mas devem constituir um sistema (ein System ausmachen)... Ora, entendo por sistema a unidade de diversos conhecimentos sob uma idéia (die Einheit einer mannigfaltigen Erkenntnisse unter einer Idee). Essa idéia é o conceito racional da forma dum todo (der Vernunftbegriff von der Form eines Ganzen), na medida em que é nele que são determinadas a priori a esfera dos elementos dive rsos e a posição respectiva das partes" ( $K r V$,A 832-B 860; tradução francesa, p. 558). Tal é a concepção kantiana do sistema, e tal também a estrutura gueroultiana, segundo Guillermit: "que a essência filosófica das obras seja reconhecida por aquilo que comportam de sistemático, e que o sistema consista na eficácia de uma 'unidade capaz de transformar o agregado de uma diversidade numa organização onde a Idéia do todo determine a priori as relações entre as partes" (GUILLER- 
MIT, 1977, pp. 302-303), eis o que motiva a máxima segundo a qual se deve regrar a interpretação das filosofias "não pela representação que delas dão os seus autores, mas pela Idéia, que encontramos fundada na própria Razão, da unidade natural das partes por eles reunidas" (GUILLERMIT, 1977, p. 303; o texto citado é o da $K r V$, A 834 - B 862, tradução francesa, p. 559); donde a possível superioridade do intérprete, capaz de fazer aparecer, em toda a clareza, a concepção que um autor não tornou efetiva o bastante (GUILLERMIT, 1977, p. 303; o texto citado é o de $K r V$, A 834-B862). Conclusão: "tais são as concepções que a Arquitetônica da primeira Crítica expõe e que podem ser facilmente discernidas no princípio da constituição da história da filosofia da Tecnologia dos sistemas".7 E tal é de fato uma das máximas, a primeira, que Louis Guillermit encontrará em Kant como guia de sua própria leitura estrutural da Crítica do Juízo: "É lastimável que somente depois de ter passado longo tempo, guiados por uma Idéia oculta em nós, a reunir rapsodicamente, como materiais de construção (als Bauzeng), muitos conhecimentos que a ela se reportam e mesmo somente depois de tê-los por muito tempo composto tecnicamente (tecnisch zusammengesetzt haben), nós sejamos enfim capazes de ver a Idéia a uma luz mais clara e de conceber arquitetonicamente o plano de um todo segundo os fins da razão. Dir-se-ia que os sistemas se formam como os vermes, por geração equívoca: eles nascem da simples conjunção de conceitos reunidos (Zusammenfluss); de início truncados, eles se completam com o tempo (mit der Zeit vollständig); e, no entanto, seu conjunto possuía um esquema, a título de germe originário (ursprünglich) na razão que não faz outra coisa senão se desenvolver (der sich bloss auswickelnden Vernunft)" (KrV,A 834-835 e B 862-863). ${ }^{8}$

Em segundo lugar, a unidade técnica, aquela de que A ristóteles já assinalara o parentesco, na estrutura do muthos trágico ${ }^{9}$, com a estrutura dos organismos vivos em termos quase integralmente reproduzidos pouco mais acima na Arquitetônica, é articulada com a unidade orgânica da metafísica, cujo conceito exige que nela seja, ou tudo, ou nada: "A razão pura é uma unidade inteiramente à parte (ganz abgesonderte) e que se basta a si mesma (für sich bestehende), na qual cada membro, como num corpo organizado, existe para todos os outros e todos para cada um, e na qual nenhum princípio pode ser tomado com certeza, sob um ponto de vista, sem ter sido examinado no conjunto de suas relações com todo o uso da 
razão" (KrV, Prefácio da segunda edição, B XXIII-XXIV). ${ }^{10}$ É essa unidade orgânica que o conceito de estrutura confere à filosofia do sistema: cada sistema não está apenas articulado segundo uma idéia, mas está ligado aos outros numa unidade harmoniosa, como o estão os membros de um mesmo todo, do qual cabe à forma crítica da metafísica como ciência desenhar a forma arquitetônica de conjunto. É bem este o objeto da dianoemática gueroultiana.

Mas se nessas condições, como também observou Victor Goldschmidt numa nota do seu sistema estóico (GOLDSCHMIDT, 1953, p. 20; e, para um comentário do capítulo 7 da Poética, GOLDSCHMIDT, 1982, em particular, p. 253), a idéia moderna de estrutura dos sistemas lingüísticos ou etnológicos, nos quais a consideração do todo comanda a das partes, foi antecipada pela filosofia das estruturas já desde a unidade do muthos trágico aristotélico até a do sistema estóico, e sobre um mesmo modelo orgânico da categoria, será então que se poderia encontrar, tanto na Primeira Crítica em particular quanto no conjunto da obra crítica, uma aproximação dessa filosofia das estruturas, primeiramente como organicismo e apenas subsidiariamente como idealismo, com uma filosofia da subjetividade?

Os autores franceses que evocamos no início talvez o tenham crido. Lembremos o aval dado por Lévi-Strauss na Abertura das Mitológicas a um Paul Ricoeur que havia caracterizado a démarche lévi-straussiana como um "kantismo sem sujeito transcendental" (LÉVY-STRAUSS, 1964), fazendo a seguinte precisão: "Trata-se mais de um inconsciente kantiano que de um inconsciente freudiano, um inconsciente categorial, combinatório... sistema categorial sem referência a um sujeito pensante... homólogo à natureza; talvez ele seja natureza" (RICOEUR, 1963, de que Lévi-Strauss cita as páginas 9 e 10). E pôde-se, de fato, acreditar que estrutura - sob suas formas formais, lingüísticas ou lógicas e até matemáticas - significava precisamente uma substituição do sujeito por esse "pensamento objetivado", mas produtor de ordem e movido por uma necessidade oculta sob suas aparências subjetivas. Como escreveu Gérard Lebrun pouco depois da morte do amigo de trinta anos, foi tal alternativa às filosofias transcendentais que teria sido buscada por Michel Foucault na filosofia que se anunciava com O Nascimento da Clínica, filosofia cujo adversário, no qual se confundiam idealismo alemão e 
fenomenologia, teria, sem dúvida, sido mais claramente identificado então pelos primeiros leitores de Foucault, e talvez por ele mesmo, do que de fato visado e atingido na realização efetiva da obra foucaultiana da maturidade, que renovava com uma tradição de filosofia dos historiadores da filosofia, mesmo se em benefício de uma inspiração nietzschiana que mandava revisitar as filosofias antigas do cuidado de si... Por fim, ainda mais surpreendentes foram as tentativas feitas desde a epistemologia de Marbungo até certas correntes saídas do logicismo de Frege, Carnap e Wittgenstein, de delegar as atri buições daquilo que o idealismo alemão chama de pensamento, consciência ou poderes do espírito, àquilo que a linguagem ou a lógica matemática ofereciam como referencial categorial ou horizonte da razão pura, transcendental, sem sujeito.

Pode-se, todavia, garantir a jurisdição das estruturas sobre os sistemas, tanto na concepção que Kant tem do sistema estruturado da metafísica, quanto no poder explicativo dessa jurisdição para a explicação do sistema kantiano, se se dissocia a unidade orgânica, ou técnica, da unidade do pensamento? Eis o que parece inteiramente impossível, por duas razões pelo menos:

Em primeiro lugar, a unidade do todo depende de um esquema que determina a priori segundo uma Idéia, e não apenas empiricamente segundo um objetivo exterior, o conteúdo do pensamento. É precisamente nisso que, enquanto tratado do método e não de sistema da ciência, a metafisica sob sua forma crítica é um inventário sistematicamente ordenado e, por isso, necessariamente completo, embora de seu próprio poder, cuja completude só pode ser garantida pela teleologia interna. Já no Prefácio à primeira edição Kant escreve que "aqui nada pode nos escapar, já que aquilo que a razão tira inteiramente de si mesma não pode lhe permanecer oculto" ( $K r V$,A XX; tradução francesa, p.10). O Prefácio à segunda edição faz a exaustividade do inventário depender diretamente da revolução copernicana: "no que diz respeito a esse ponto", e o texto remete a "eine gänzliche Revolution", "no conhecimento a priori nada pode ser atribuído aos objetos senão aquilo que o sujeito pensante tira de si mesmo" (KrV, B XXIII; tradução francesa, p. 21).

Em segundo lugar, enfraquecer o poder do espírito, como quer a epistemologia racionalista neokantiana ou sua transposição logicista, fazendo dele uma "condição de possibilidade" neutra em relação à idealidade 
desse poder, significa limitar o idealismo crítico a uma crítica transcendental da ciência. Ora, Kant sublinhou vigorosamente que esta última, para seguir o seu caminho, pode prescindir da crítica transcendental tanto quanto de uma crítica do gosto, ou seja, a crítica só existe como preparação à metafísica. Perdeu-se, assim, de vista o que finalmente estava em jogo no pensamento crítico. Mas se perdeu igualmente, e talvez mais decisivamente, o conteúdo mesmo desse pensamento, de uma arquitetônica que comanda a pluralidade dos sistemas. Com efeito, só a referência ao poder do pensamento constituinte ou reflexionante permite garantir o duplo estatuto de arte e de teoria à arquitetônica, da qual se diz sucessivamente, quase simultaneamente, num intervalo de apenas quatro linhas do primeiro parágrafo do capítulo que a define, que ela é arte "Kunst der Systeme" - e teoria - "die Lehre des Scientifischen in unserer Erkenntnis überhaupt” (KrV,A 832).

Ora, é justamente essa oscilação ou ambigüidade da filosofia, ora como ciência do universal e das invariantes estruturais do pensamento, ora como arte dos sistemas concretos enquanto totalidades orgânicas, que ao mesmo tempo desfaz, em Kant, a alternativa mortal entre dogmatismo e ceticismo e funda, em Gueroult, a solução da aporia com a qual é confrontado o historiador da filosofia, que tem de se haver com a perenidade de filosofias construídas e apreendidas como obras de arte em sua pluralidade sempre singular, embora sejam ordenadas por uma pretensão à exclusividade do verdadeiro, ela mesma irredutível: como afirmaVictor Goldschmidt, "o sistema visa à realidade extrínseca da ciência, mas deve se contentar com a verdade intrínseca da obra de arte" (GOLDSCHMIDT, 1953, p. 312).

Que a auto-suficiência de cada sistema seja, para uma filosofia, a única garantia de uma permanência no tempo comparável à das obras de arte; que, ao mesmo tempo, visar uma verdade que seja única é o que anima a sua construção em meio à discórdia instaurada entre todas elas, em suma, que se possa vislumbrar uma "paz perpétua" nos limites críticos, disso não restaria mais nada uma vez suprimido o idealismo subjetivo, isto é, uma vez relegados à contradição objetiva ou formal pensamentos sistemáticos dos quais se tivesse eliminado tudo o que lembrasse arte, no sentido da atividade de si sobre si. Aquele, diz Kant, que possui apenas o conhecimento de uma verdade racional objetiva, ainda que do sistema inteiro de 
Wolff, mas não subjetiva, extraída das fontes da razão, é alguém que "apreendeu e reteve bem, isto é, aprendeu" (Er hat gut gefasst, un behalten, d. i., gelernt), "ele é a máscara de um homem vivo" (und ist ein Gipsabdruck von einem lebenden Menschen) (KrV,A 836-B 864). ${ }^{11}$ Ora, há no sistema de Kant outra fonte de vida para as estruturas, encarnadas mas não imobilizadas nos sistemas, que o pensamento, posto, como na arte, no princípio de seus produtos?

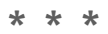

\section{O sistema kantiano e a vida das estruturas no idealismo crítico}

É precisamente essa vida das estruturas que predispunha o sistema crítico de Kant a fornecer o paradigma do método estrutural em história da filosofia e que, ao mesmo tempo, permite a esse último uma aplicação magistral à filosofia transcendental, na medida em que esta é uma filosofia da subjetividade - e não a despeito de sê-lo, como pretendia o tema marburguiano da maldição que pesava sobre o vocabulário das faculdades do espírito, tema ainda vivo na pena do Husserl das Investigações Lógicas (HUSSERL, 1901, Prolegômenos, \38, p. 124; trad. p. 137, e COHEN, 1918, Posfácio, pp. 785-786; tradução, p. 602).

Aqui se esclarecerão melhor, ou se enriquecerão de precisões inteiramente novas, as razões que levam Gueroult a ser tão sensível às injustiças ou àquilo que havia de literalmente inexato na interpretação hegeliana do estrutural, categorial ou sistemático em Kant. Deixando por ora de lado a questão de saber se essa sensibilidade é causa ou efeito do ponto de vista a partir do qual o método das estruturas observa os sistemas de filosofia e da defesa gueroultiana de um "idealismo radical" contra o idealismo absoluto, questão que nos ocupará no final, voltemo-nos para a aplicação da "tecnologia dos sistemas" ao sistema kantiano. Guillermit havia notado, desde 1977, que ela não havia sido diretamente proposta pelo próprio Gueroult, cujo conjunto de monografias históricas e cuja teoria dianoemática atestam um kantismo onipresente, mas indireto. É na obra póstuma de Louis Guillermit consagrada à Elucidação crítica do juízo de gosto em Kant que se encontrará essa aplicação direta. A reconstituição 
paciente da unidade orgânica do sistema supõe, no grande intérprete, não tanto a exploração que naquele mesmo momento levava um Gérard Lebrun $^{12}$ a diagnosticar o surgimento dos temas, embora o conduzisse a conclusões idênticas quanto à importância insubstituível da terceira Crítica para a avaliação do sentido final da doutrina: a reconstituição paciente da unidade do sistema supõe antes a elucidação crítica da progressividade da constituição viva do sistema do idealismo kantiano, que liga a retomada crítica das articulações do sistema por ele mesmo à intussuscepção de seu sentido, e a passagem da primeira Estética (da Crítica da Razão Pura) à Estética da terceira (da Crítica do Juízo), na articulação estrutural entre ambas, à culminação do idealismo crítico, entendido como filosofia da razão afetada sensivelmente. Nesse seu papel maior, e não coadjuvante e até contingente, que a subjetividade desempenha no princípio de animação do sistema, trata-se de desenvolver o sentido da vida das estruturas, guardando mais uma vez distância das objeções fichtianas e hegelianas, ou das caricaturas de um Schopenhauer, endereçadas a um idealismo que teria permanecido ainda excessivamente dogmático e objetivante, ou que correria excessivamente o risco de ser tomado de ternura pelo sensível, impondo, sem necessidade, limites à auto-aplicação do pensamento a si mesmo ou, enfim, a um idealismo deformado até a compulsão de morte por uma concepção abstrata e combinatória das categorias objetivadas, e isso mesmo na Crítica do Juízo reflexionante, ainda que esta última esteja livre da relação ao objeto.

Se, com efeito, para Louis Guillermit é preciso esperar a Terceira Crítica para ver o sistema transcendental kantiano completar o seu sentido, é porque nele opera uma teleologia interna, cujo movimento que a elucida, assim como a efetividade do conceito hegeliano, não se apresenta como uma variação inessencial ou até como uma roupagem contingente com a qual os sistemas, ora crítico, ora dialético, teriam vestido invariantes hipostasiadas em abstrato, e que permaneceriam veladas aos olhos do construtor do sistema em razão de sua submissão à contingência temporal.Trata-se, antes, de uma teleologia orgânica, de uma vida das estruturas, de que somente uma epigênese, e não uma pré-formação, mesmo no ideal, poderia prestar contas à Razão. ${ }^{13}$

Contra as assimilações abusivas da estrutura gueroultiana à estrutura bourbakista, d e nunciadas com efeito por G.-G. Granger, é preciso em 
particular ter a medida da resistência nativa da estrutura, obra do pensamento subjetivo, à objetivação, mesmo que ideal, e isso justamente em nome de recursos de um pensamento que não somente idealiza, mas constitui a priori o objeto sensível do conhecimento, que experimenta a autodeterminação absoluta da Lei na decisão prática e que, finalmente, na Crítica do Juízo, liberta o livre jogo da subjetividade de todo constrangimento objetivo. As críticas endereçadas ao método gueroultiano em nome de uma história historiante ou viva coincidem exatamente com aquelas feitas à abstração formalizante do categorial ou racional kantiano. Nos dois casos se esquece que, em Kant, a estrutura é animada por uma teleologia, cuja progressividade é de essência, que ela tira seu paradigma da arte ou da vida; como a estrutura gueroultiana, que de início se pratica e põe à prova no movimento de animação interna das estruturas da Doutrina-da-ciência fichtiana, deve necessariamente contar, no fichtianismo, com uma filosofia da vida do racional e consentir, por isso mesmo, a ver nele um momento da marcha em direção ao idealismo absoluto de Hegel; e como, em seguida, refletida na dianoemática, ela proporá um idealismo radical, proclamando a auto-suficiência daquelas construções racionais sempre singulares, que sempre dão novamente a norma de si mesmas, que são os sistemas filosóficos: nos antípodas da suposta redução dos pensamentos vivos a quadros inertes, nesses sistemas a estrutura marcava, desde a grande monografia sobre Descartes, a submissão da ordem das matérias à ordem das razões, réplica fiel da submissão da unidade do ser à ordem do pensar no Cogito fundador da forma moderna de idealismo. E não é diferentemente que o Espinoza de Gueroult tentasse separar a visão objetivante do mos geometricus, a hesitação mortal entre a natureza e o absoluto, d evolvendo articulação e vida à demonstração, órgão ativo da visão intuitiva.

Em se tratando da filosofia crítica, foi Louis Guillermit quem circunscreveu a máxima interpretativa que lhe é ao mesmo tempo interna e própria para iluminar sua unidade orgânica, unidade esta que pode e deve de início aparecer apenas de uma maneira truncada ao construtor do sistema. Se o próprio Gueroult não identificou a sua fórmula, foi talvez porque ela não é senão aquilo que ilumina seu próprio método de historiador e porque, como se verá, ela singulariza por isso mesmo essa metodologia universal que pretende culminar na dianoemática. Pela 
afinidade desta com o idealismo crítico é mais que claramente compre ensível que, construindo contra Hegel um "idealismo radical”, ela revelasse justamente, ou uma preferência, ou uma reserva radical, que dizem mais respeito ao filósofo Gueroult que ao historiador das estruturas...

Essa máxima, que dá título à obra póstuma de Louis Guillermit, é a da elucidação crítica, e ela se explicita no Prefácio como sendo aquilo que orienta a segunda parte da obra (GUILLERMIT, 1986, pp. 9-10), a qual, por sua vez, precisa aquela máxima pela escolha de sua epígrafe, e acaba de esclarecer a escolha do texto tirado da Arquitetônica. Ela não chama atenção apenas, negativamente, para a geração equívoca, truncada, mas, positivamente, para a elucidação crítica como elemento mesmo do sistema. Se a forma crítica do idealismo proporciona um tratado do método antes de proporcionar uma ciência, ela impõe a seu autor não somente, e de início, uma concepção totalizante do saber subjetivo, mas uma concepção transcendental da justificação da organicidade desse conhecimento. Longe de ser culpado, como pretende o fichtianismo, de não ter posto o seu dizer em acordo com o seu fazer no plano teórico, o que o kantismo pretende é abrir para a crítica, e não para a reflexividade, de sua sistematicidade especulativa uma processualidade sistemática, rejeitando, antes de tudo, aquilo que não lhe pode aparecer, na empreitada fichtiana, senão como um retorno ao dogmatismo arrogante das doutrinas em que a Lehre exorbita da crítica. O kantismo não é vítima da finitude da subjetividade do entendimento, falando a língua de uma Razão que se encontra submetida à inércia do categorial: ao contrário, é justamente numa vida da Razão que se desvela a auto-elucidação do sentido do sistema por ele mesmo, mais essa via é crítica, ou seja, ela é exame tanto quanto legitimação (Prüfung und Rechtfertigung) de um pensamento puro que se experimenta como arte e trabalho sobre si: afetado sensivelmente, esse pensamento se descobre em sua essência crítica quando ele se reconhece "heautônomo", afetado não pelo objeto ou pela representação do objeto, sensível ou supra-sensível, mas por sua própria atividade.

Sendo assim, o ponto de vista justo para observar os "deslocamentos" da arquitetônica kantiana não é aquele que Hegel havia obtido por uma reconstrução feita do exterior. Isso Gueroult já o dissera, negativamente, tanto nos estudos que visavam Kant através de suas interpretações fichtiana e hegeliana, citados por Guillermit na revista Archiv, como 


\section{4}

também no estudo diretamente consagrado a Kant (GUEROULT, 1954; mas também GUEROULT, 1931, pp. 413-439 e GUEROULT, 1971, pp. 47-80). Foi Louis Guillermit quem mostrou qual era, positivamente, esse ponto de vista justo, ao fazer da "elucidação crítica" (kritische Beleuchtung) - a necessidade dela já se delineia justamente a partir da Segunda Crítica - a máxima da reconstrução interna, teleologicamente ordenada, do acabamento progressivo do sistema por sua estrutura. Kant havia, com efeito, denominado "elucidação crítica" "o exame e a justificação das razões pelas quais uma ciência ou uma de suas seções, constituindo nela mesma um sistema, deve ter precisamente essa forma sistemática e nenhuma outra, se a comparamos com outro sistema que tem por fundamento uma faculdade de conhecimento comparável" (KrV, 159; trad. Picavet, p. 95). ${ }^{14}$ Guillermit a aplica à constituição progressiva do sentido crítico da Estética através das três Críticas. É pela conquista total de um sentido inicialmente truncado da Estética como crítica, e de uma filosofia em que a crítica faz as vezes de teoria sem se conceder a arbitrariedade de um ponto de partida contingente em relação a sua forma própria de auto-afecção, que deverá se justificar o princípio de unidade do sistema como atividade do espírito, mas unidade reflexionante, não substancial, e como crítica, não como doutrina da reflexão ou da processualidade."A dedução da divisão (Einteilung) de um sistema, isto é, a demonstração de sua integralidade (Vollständigkeit), assim como de sua continuidade (Stetigkeit), isto é, da passagem (Übergang) dos conceitos divididos aos membros da divisão sem solução de continuidade (divisio per saltum) na série inteira de subdivisões, é uma das condições mais dificeis de satisfazer para o construtor de um sistema" (KANT, Metafísica dos Costumes, Primeira Parte, Introdução, III, nota 1. Citado em GUILLERMIT, 1986, p. 59, e 1976, p. 125). É desse texto, posto como epígrafe da segunda parte de seu livro, que Guillermit espera obter a indicação do método a ser seguido na reconstituição do sentido final da Estética.

Coube a Jules Vuillemin, na notável Introdução que escreveu a essa obra póstuma, trazer à plena luz a adequação perfeita assim encontrada pelo autor entre o método de elucidação crítica e o movimento mesmo de constituição do sistema do idealismo kantiano, que se mostra de maneira exemplar no estabelecimento progressivo de uma estética do sentimento, solidária de uma clarificação por etapas do sentido de uma 
metafísica como crítica. O sentimento se mostra de início como sentido (Sinn), ou como aquilo que nossos conhecimentos comportam de subjetivo enquanto referido a um objeto; depois, no sentimento moral, como desligado desse tipo de representação do objeto e apreendido como efeito possível da razão sobre a subjetividade; e somente por fim ele se mostra no sentimento desinteressado como separado do interesse suscitado pelo esforço moral e definido pelo puro estado subjetivo da mente (Gemütszustand), no qual a reflexão toma consciência do exe rć́cio de nossas faculdades. Da mesma maneira e simultaneamente, a crítica do juízo de gosto só aparece no centro da invenção crítica em geral uma vez eliminada a suposição inicial de que um domínio particular constitua o exe rcício legítimo da faculdade de conhecimento. $\mathrm{O}$ ponto de partida de Guillermit, segundo Vuillemin, era a constatação feita de diferentes maneiras pelos grandes sucessores de Kant: "propor leis próprias a priori para a Estética da faculdade de conhecer" era, decerto, realizar uma revolução copernicana, trocando as posições respectivas do objeto e do sujeito do conhecimento. Mas era, ao mesmo tempo, fazer essa revolução depender de uma condição finalmente acessória" (VUILLEMIN, 1986, p.VI). Guillermit teria mostrado, por contraprova, que se cada um desses sucessores pretendeu, à sua maneira, se liberar dessa condição acessória, isso não se fez sem que se excedessem os limites que o princípio mesmo da revolução copernicana fixa para o método, nem sem que faltassem com a paciência própria à estrutura ou ao sistema, a única que lhes teria revelado a maneira original pela qual o sistema de Kant, exercendo sobre si mesmo as extensões e purificações exigidas pela elucidação crítica, opera em seu seio a renovação interna de sua própria revolução copernicana. “A Estética da Faculdade de Julgar é a chave da abóboda do edifício kantiano, não porque ofereça a solução da unidade enigmática do conceito e da intuição ou porque abra o caminho para a intuição intelectual subjetiva ou objetiva, ou porque ofereça o esboço da vida própria ao conceito absoluto" (idem, ibidem). E sabe-se que defesa Kant julgou necessário mobilizar contra as sugestões que seus amigos faziam para que se fosse em tais direções: "Ela é a chave da abóboda porque, no momento em que o entendimento que conhece e a razão que age transmitem um ao outro seu duplo impulso, eles não encontram apoio recíproco senão numa faculdade de julgar, 
onde o sujeito ousou se libertar dos apoios externos e dos contrafortes do objeto e do desejo" (idem, ibidem).

Mas a adequação perfeita aqui alcançada entre método e objeto seria suficiente, tão univocamente como o propõe Jules Vuillemin, para que se apreenda o sentido inscrito em germe na estrutura do idealismo subjetivo de Kant? Não seria ela comandada, e limitada, a parte ante, pela escolha que o método das estruturas faz de um "idealismo radical" contra o idealismo absoluto? Pode-se seguir a idéia aqui proposta por Jules Vuillemin, de uma definição da "forma do incondicional e do absoluto própria à filosofia de Kant" como sendo "uma segunda revolução copernicana, pela qual as faculdades do sujeito devem ser consideradas por abstração dos constrangimentos que sofrem em virtude de suas relações particulares com o objeto" (idem, ibidem)? Aqui parece necessário introduzir a questão da gênese das estruturas sistemáticas, que evocaremos num último momento com uma intenção duplamente interrogativa. Essa questão, efetivamente, diz respeito tanto aos limites do método gueroultiano quanto àqueles da apreciação, tanto interna quanto externa, que ele apresenta da forma sistemática do idealismo kantiano.

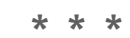

\section{0 idealismo kantiano e a gênese das estruturas}

Para aqueles que nos seguiram, parece claro como o sol que o idealismo radical de Gueroult, longe de opô-las, liga estrutura e subjetividade num sentido que o autor pretendia mais "radical" que o do idealismo absoluto, a ponto de fazer da auto-suficiência de cada filosofia, no seio do racional assim visado, a solução da aporia entre ciência e art e. Sobre esse idealismo radical de Gueroult, Bernard Bourgeois fez notar recentemente, num texto tão retumbante quanto mal conhecido, ou pouco citado (BOURGEOIS, 2001, pp. 185-197) ${ }^{15}$, que ele deixa sem solução o problema da gênese das estruturas, que, nele, escapam a toda e qualquer gênese.

Se, com efeito, é nas estruturas que se pensa, e não no conteúdo empírico ou histórico delas - mesmo que as monografias gueroultianas sempre se mostrem de uma curiosidade excepcionalmente bem docu- 
mentada e que levava o autor da Dianoemática a se dizer, de maneira bem imprudente, que era mais historiador que Hegel, porque, pensava ele, mais preocupado com a efetividade singular e textual (o que é passível de discussão) -, as estruturas auto-suficientes de Gueroult não fornecem a chave de sua gênese no seio da história racional da filosofia, pois a Dianoemática enquanto "disciplina se refere às condições de possibilidade das filosofias (dianoema, doutrina) como objetos de uma história possível" (Gueroult citado por GOLDSCHIMDT, 1977, p. 306; fórmula comparável em GUEROULT, 1984-1988, p. 66). Não há como não seguir o convite que Bernard Bourgeois nos faz a nos interrogarmos sobre a dimensão efetivamente histórica de um idealismo que, em sua filosofia da história das filosofias concretas, pretende substituir a radicalidade de um saber absoluto ao qual se censura ter partido de seu próprio sistema para dele deduzir a realidade da história da filosofia, pela radicalidade de uma "experiência filosófica" que é vivida "pelo pensador como livre criação de uma totalidade autodemonstrada do sentido" (BOURGEOIS, 2001, pp. 190-191, que comenta GUEROULT, 1984-1988 , p. 224). Ao buscar, com efeito, na Crítica kantiana, como bem o viu Guillermit, o modelo para compreender essa filosofia da história da filosofia, que, segundo ele, exigia que se prolongasse a "revolução" hegeliana numa segunda revolução ainda por fazer, e ao querer radicalizar o idealismo absoluto numa modulação crítica, parece mesmo que quem se exprime é o filósofo Gueroult, que marca sua preferência por Kant contra Hegel, e não o historiador Gueroult que julga o historiador Hegel.Vemos que a Dianoemática concede à experiência filosófica os plenos poderes de um idealismo subjetivo, e que não se trata de forma alguma de abdicar de suas pretensões em nome de exigências filológicas ou de historicidade empírica. Trata-se de radicalizar um idealismo que ainda não o é o bastante enquanto permanece idealismo absoluto. Se, com efeito, o primeiro capítulo da Dianoemática situa o projeto e a Idéia de Dianoemática no cruzamento dos dois critérios, positivo e transcendental, e se a necessidade do primeiro é lembrada com insistência contra Hegel, ela o é também contra Kant e contra aquilo que sua posição do problema da possibilidade da metafísica como ciência conserva de um dogmatismo contrário à sua intenção profunda: "O destino da filosofia kantiana testemunha contra sua pretensão de conferir à filosofia uma 
estrutura definitiva mediante sua forma científica... A filosofia de Kant, não mais que a de Reinhold, de Fichte, de Hegel, não conseguiu, mediante sua forma científica, pôr ponto final à história" (GUEROULT, 19841988, pp. 68-69) ${ }^{16}$. E não o conseguiu, porque aqui Kant subverteu a questão do direito, submetendo-a, na verdade, a uma decisão de fato sobre a nulidade objetiva das metafísicas existentes e sobre o valor objetivo das matemáticas e da física (GUEROULT, 1984-1988, pp. 68-69).É, portanto, uma insuficiência do idealismo que motiva aqui o déficit de positividade, se por positividade se entende a tarefa de avaliar as filosofias e não somente as ciências, tais quais elas são, e se nessa submissão ao fato da existência das metafísicas se retém não apenas a sua discórdia, mas também sua pretensão, distinta, certo, daquela da ciência, mas igualmente legítima (GUEROULT, 1984-1988, p. 69). ${ }^{17}$

Essa radicalização do idealismo, ou da revolução copernicana, supõe efetivamente, por sua vez, um postulado, isto é, a resposta positiva à questão de fato, a da existência de uma metafísica dada como tal na história e possuindo um valor próprio. Postulado admitido, diz Gueroult, pelos historiadores da escola objetiva; postulado, em contrapartida, cuja natureza de postulado inelutável evita que se tente convencer os céticos da validade dele. Gueroult se exprime sem nenhuma ambigüidade sobre sua decisão por essa forma de idealismo: "Como cada um deles, Platão e Fichte, disse à sua maneira: há duas classes de homem: uns acreditam na 'coisa sensível' antes de acreditar nas 'Idéias'; outros acreditam nas 'Idéias' antes de acreditar na 'coisa sensível'. Se faltam as condições que tornam necessária a crença na realidade das Idéias, a crença sensível ocupará todo o campo do pensamento, sem nada deixar para a crença na realidade das Idéias. Se, ao contrário, essas condições se apresentam, a crença na realidade das Idéias se manifesta e limita, na mesma medida, a crença na realidade sensível." (GUEROULT 1984-1988, p. 71) E é ainda num espírito fichtiano que Gueroult faz sua a escolha de um idealismo como escolha da liberdade: "Por outro lado, se a especulação que se desenvolve ao infinito na história é o lugar da realização da liberdade sob a forma mais elevada de liberdade criadora da inteligência, a crença na realidade das Idéias, de que essa livre inteligência é o órgão criador, deve supor um ato de liberdade, para que apareçam as condições que a tornam necessária. A realidade das Idéias, que a especulação nos apresenta na história, sob 
forma de doutrinas, deve pois se tornar objeto de um livre postulado, diante da livre negação do cético"18.

Se, portanto, é a decisão idealista que deve fundar a "experiência filosófica em sua realidade viva” (GUEROULT, 1984-1988, p. 224), do que Gueroult está convencido, ele se empenha nisso fazendo da experiência filosófica para cada sistema a "consciência que o filósofo tem 1) de sua livre invenção de um conteúdo intelectual justificado por sua totalização; 2) da ve rdade eterna desse conteúdo apreendido como uma Idéia... 3) da inserção nessa Idéia e, como essencial a ela, da sua liv re revelação a si mesma no ato filosofante" (BOURGEOIS, 2001, p. 191, comentando GUEROULT, 1984-1988, pp. 192-195). Essa decisão nos leva certamente, em Gueroult, além de Kant e até de Fichte, com quem ele pôde certamente "instruir-se" acerca do círculo intransponível do idealismo e do realismo ${ }^{19}$ que é resultado dessas três condições, círculo de uma filosofia sempre engajada e decidida a partir do centro da liberdade. "É preciso convir, por conseguinte, que o ato do pensamento filosofante subjetivo aparece simplesmente como condição de possibilidade para a revelação da Idéia no pensamento filosofante. Ora, como a Idéia faz parte do conteúdo objetivo desse pensamento, tal revelação é, para esta, uma revelação para si mesma, ou uma revelação da Idéia para si mesma... Logo, a condição que torna essa revelação possível deve ser, ela também, eternamente necessária. Ora, essa condição é um ato livre e contingente, por meio do qual a Idéia é estabelecida como tal pelo pensamento filosofante. Esse ato livre e contingente, enquanto liv re e contingente, é por conseguinte eternamente necessário”(GUEROULT, 1984-1988, p. 193). Essa definição da experiência do sistema filosófico já nos fez sair de Kant, mas também de Platão, e é manifesto o empréstimo que faz a Fichte. Contudo, ela não pode permanecer aí. Ela nos leva até Hegel, não porque se trate explicitamente, para Gueroult, de "inverter" o sistema deste, mas porque é precisamente a "estruturação formal do saber absoluto hegeliano que se encontra na experiência gueroultiana refletindo sobre si mesma: o Espírito absoluto se torna precisamente a unidade de si mesmo e do espírito finito numa tal experiência realizada em todo filósofo" (BOURGEOIS, 2001, pp. 191-192).

Mas se a "Idéia se põe como real desde toda a eternidade e como fonte eterna do ato pelo qual ela foi liv remente posta, como real, num 
dado momento do tempo" - o tempo da sucessão das filosofias (GUEROULT, 1984-1988, p. 195) -, a estruturação formal do saber absoluto hegeliano assim assumido é entendida, em Gueroult, sem, no entanto, eis o segundo momento da comparação de Bernard Bourgeois (2001, p. 192), que se conceda a essa experiência filosófica o estatuto de saber absoluto. E isso não em nome da razão proposta, negativamente, por Gueroult (por exemplo, em GUEROULT, 1984-1988, p. 224), com o intuito de inverter um sistema que parte de si mesmo para deduzir a realidade da história da filosofia, em vez de buscar o inverso, mas em nome da diferença que chama a atenção de qualquer leitor da metafísica clássica, tanto quanto do leitor de Hegel: em Gueroult, cada sistema constitui como que uma Idéia e um saber absoluto, entre os quais o saber constituído pela reflexão gueroultiana da história da filosofia estabelece uma igualdade. "De tal maneira, escreve Bourgeois, que o monismo ou monarquismo ou monoteísmo do saber absoluto hegeliano é substituído por um pluralismo, por um aristocratismo, por um politeísmo gueroultiano dos saberes absolutos" (BOUR GEOIS, 2001, p. 192). Gueroult se mantém aqui num recuo fichtiano em relação à filosofia da unidade da unidade e da diferença: "As calmas figuras dos deuses intelectuais gueroultianos já não trazem em seus semblantes o traço nostálgico que Hegel lia sobre as estátuas sensíveis dos deuses gregos, pois sua multiplicidade é a dos sistemas plenamente auto-suficientes ou - termo bem fichtiano! - autárcicos." (BOUR GEOIS, 2001, p. 192) Mas, então, como compatibilizar a exigência da estruturação formal, de tipo hegeliano, para o medium da história filosofante, e o estatuto de tal medium, que remonta a bem aquém de Kant? Eis a dificuldade que Bourgeois sugere sem afirmar, ao constatar a dupla ausência, de uma necessidade antecedente que limite a posição essencial desses sistemas autárquicos, ou de uma necessidade conseqüente que freie a composição existencial deles (BOURGEOIS, 2001, p. 192).

Ausência de necessidade antecedente, pois esse pensamento divino que abriga em si as Idéias sistemáticas não é concebido como se ele os pensasse realmente; o Deus dos sistemas assim autonomamente divinizados "não é leibniziano, nem a fortiori hegeliano, ele é berkeliano; os deuses se encontram empiricamente nele, simples suporte liberal de sua autocriação tornada então absoluta" (BOURGEOIS, 2001, p. 192). Mas se é assim, com essa recusa do hegelianismo, o Gueroult da Dianoemáti- 
ca não está decididamente condenado a evocar com ternura, como afirma ainda Bernard Bourgeois, a primeira concepção hegeliana do Escrito sobre a Diferença dos Sistemas de Fichte e de Schelling, no qual Hegel comparava a filosofia a uma obra de arte, então caracterizada como um absoluto e não como um momento do devir do absoluto ${ }^{20}$, e, portanto, condenado a tornar sem efeito a pretensão do idealismo radical a fornecer uma alternativa àquilo que, na concepção hegeliana, está resolutamente além das filosofias da diferença ou da unidade?

Se, de fato, a alternativa que ele propõe parece bastante distante de poder resolver o problema da invenção das estruturas no interior dessa história filosofante, pode-se, em contrapartida, pensar que o exemplo da filosofia de Kant, justamente à qual ele não consagrou nenhuma monografia, propunha ao método gueroultiano de Louis Guillermit ao mesmo tempo um problema particularmente árduo, pois era preciso extrair dessa filosofia, como Gueroult o fizera para Descartes e Espinoza, a máxima interpretativa que podia lhe convir singularmente, mas não se podia abrir mão da distância necessária à interpretação, já que aqui a doutrina era também crítica; além disso, porque a crítica não é diretamente em Kant aquilo que será em Fichte, a própria máxima não tematiza esse distância, a ser reabsorvida, entre um dizer e um fazer teóricos. Por outro lado, esse problema também era uma solução, dado o parentesco do método crítico e do método estrutural, para o qual era preciso encontrar simplesmente, se podemos ousar dizê-lo, um meio de esclarecê-los reciprocamente enquanto tais, e não fazendo de um o objeto impossível do outro. Parece-nos que o método de elucidação crítica opera esse tour de force de uma interpretação "estrutural" do idealismo crítico. Nesse sentido, ela nos convida a interrogar sobre a resposta que se pode e mesmo se impõe dar, no interior do próprio sistema kantiano, ao problema da invenção das estruturas, já que, como se viu, o que Kant inventa e corrige do interior, quando passa da Primeira à Terceira Crític a, são precisamente as estruturas.

Por outro lado, resta ainda o outro problema que a Dianoemática deixa pendente, o da necessidade conseqüente ou da inserção da filosofia numa história geral, à qual sem dúvida o saber absoluto hegeliano, rejeitado por Gueroult como dogmático e anistórico, faz mais sacrificios que o idealismo autárquico, justamente porque se sacrifica a ela. Sobre esse problema, Jules Vuillemin pôde fornecer uma clarificação da Primeira 
Crítica inspirada no método estrutural, clarificação que não se encontrava à disposição do idealismo radical. Tal é, com efeito, sua interpretação do sistema das categorias na grande obra de 1955, na qual defende a estrutura das categorias contra a censura que Hegel lhes endereça, ao ver nelas a inércia do pensamento do entendimento. A interpretação de Vuillemin põe à luz uma teleologia do pensamento do movimento (a Mecânica racional) a partir do movimento do pensamento e, portanto, uma animação recíproca lida na concordância-discordância das duas exposições kantianas, que a interpretação de Cohen pretendeu com boas razões censurar, segundo ele, errando, porém, ao identificar, numa trivial concordância, a exposição do sistema dos Princípios e a exposição da Crítica da Razão Pura (VUILLEMIN, 1955, pp. 25-42). ${ }^{21}$ O que se faz ali é muito precisamente uma inserção essencial da história da filosofia na história extrafilosófica. E essa história não é empírica, ou nela, como no absoluto hegeliano, o que se manifesta - aqui revelação, lá ciência - é operador da necessidade na imanência de um devir que reconcilia universal e concreto.

Jules Vuillemin exprime a teleologia em linguagem hegeliana, e é também nessa linguagem que ele exprimirá a "pressuposição" kantiana, encontrada no coração da passagem de uma categoria a outra - tentando c e rtamente distingui-la do sentido hegeliano, ou do sentido que foi largamente atribuído a Hegel na França dos anos 50. "Nenhuma dessas passagens é, pois, produzida por contradições imanentes aos estágios inferiores, como é o caso em Hegel. Se de fato o pensamento se encaminha, em Kant, de uma concepção formal a uma concepção concreta do mov imento, essa fenomenologia não está, por assim dizer, inscrita necessari amente em filigrana nas primeiras pressuposições. Só o devir da ciência revelou a possibilidade de uma física matemática, bem posterior à descoberta da geometria..." (VUILLEMIN, 1955, pp. 88-89). Assim, a vida mesma das estruturas e sua invenção não se isolam numa pura história filosófica que faça passar diretamente, e inexplicavelmente, de uma estrutura à outra no elemento do racional: para poder constituir esse elemento, ela deve fazer nele a prova de seu outro na ciência efetiva. "Ao idealismo absoluto de Hegel”, escreve Vuillemin, "para o qual as superestruturas são eternamente a verdade das infra-estruturas, o idealismo crítico opõe a possibilidade de uma espécie de vida autônoma das infra- 
estruturas, da vida dispersa da razão e de todas as aventuras da descoberta" (VUILLEMIN, 1955, p. 89). Mas se nessa dialética que especifica a matéria como movimento se faz justiça à história efetiva, pode se perguntar se também se faz justiça a um idealismo subjetivo, ou se o realismo empírico e o sentido objetivante do transcendental não triunfam em Kant, ao menos no plano do conhecimento teórico, enquanto se permanece à espera da teorização do medium da inteligibilidade dialética, ou processual, que se busca na história da ciência.

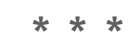

No início pusemos a questão da relação que pode ou não ligar pensamento sistemático, método das estruturas e idealismo subjetivo. Se ao termo de nossa análise podemos ficar convencidos da afinidade bastante notável e bastante singular entre o método gueroultiano das estruturas e o idealismo kantiano, este último enquanto idealismo; se a aplicação original que Guillermit pôde fazer desse método à estrutura sistemática do idealismo crítico, mediante uma reconstituição paciente das etapas necessárias em que o sistema se constitui, visa precisamente à maturação lenta e decisiva do sentido final daquilo que nele designa o subjetivo inalienável no conhecimento, a sensibilidade apreensível somente na sua profundez totalizante ao termo da Terceira Crítica, não pode ser tão claro assim que o método das estruturas tenha encontrado na Dianoemática a sua doutrina, e uma doutrina, sobretudo, em pleno acordo consigo mesma, nem que esse idealismo "radical" que a inspira possa garantir mesmo plenamente o êxito total de sua aplicação ao sistema de Kant.

A indecisão da Dianoemática, que nos reteve por fim, entre uma estrutura de tipo hegeliano, necessária ao horizonte absoluto da experiência filosófica, e a recusa de um estatuto hegeliano para esse saber sistemático em sua unidade totalizante, não era já essa indecisão, dizíamos, que fez Gueroult hesitar, ao inaugurar o método das estruturas a partir do exemplo fichtiano, entre uma leitura de Fichte feita pelo Hegel da maturidade e uma leitura feita pelo mesmo Hegel da época do Escrito sobre a Diferença? É digno de nota que, em seu artigo sobre o Fichte de Gueroult no número de homenagem dos Archiv, Jules Vuillemin assinale a dívida da 


\section{4}

tese de 1930 (escrita em 1922) para com aquilo que o aluno de Gueroult considera serem "re p resentações de sua época", a saber, a idéia "unive rsalmente aceite" de uma história do idealismo alemão que encontra sua verdade última no sistema hegeliano (VUILLEMIN, 1977, pp. 289-293). Vuillemin nota que mais tarde Gueroult julgará excessivo o papel que deu a Hegel em sua explicação de Fichte. No entanto, ele prefere reter aquilo que continuará sendo a concepção gueroultiana da necessidade da história, ao distinguir história da filosofia e história das idéias: "Pois ela (a primeira) nada mais é que o desenvolvimento de uma estrutura no tempo ou, antes, o desvelamento progressivo das condições de estabilidade de uma estrutura. Classificar uma obra entre as filosofias é, portanto, se empenhar em encontrar a razão ativa na realidade por uma espécie de "fenomenologia interna"' (VUILLEMIN, 1977, p. 293). Fenomenologia racionalista, não ilusão retrógada do verdadeiro tal qual, precisa ele, teria sido atri buída por Bergson ao racionalismo. Como conciliar então essa suposta autarcia do fichtianismo, apreendido em sua independência e não como um momento rumo ao hegelianismo, com essa necessidade da história ela mesma em seu desenvolvimento mais concreto, se justamente se recusa o hegelianismo? Será que o Hegel cuja intrusão explicativa se julgou excessiva na tese sobre Fichte é antes de tudo o Hegel da juventude, o do Escrito sobre a Diferença? ${ }^{22}$ É desse Hegel que o idealismo radical de Gueroult poderá conservar o eco, ao comparar as obras da filosofia às obras da arte, destituindo a pressuposição teológica do sistema? Mas sem essa pressuposição, que necessidade, mais uma vez, caberia a um idealismo histórico absoluto? Não é ilícito pensar que Vuillemin, que, como Goldschmidt e Guillermit, se mostrou surpreso com a publicação da Dianoemática, tenha se posto essa questão.

Ora, se essa questão não encontrava a seus olhos resposta inteiramente clara em Gueroult, e se podemos conjecturar que sua própria classificação dos sistemas busca uma alternativa tanto à Dianoemática quanto ao saber absoluto, parece-nos claro que ele havia encontrado na aplicação do método das estruturas ao sistema de Kant por Louis Guillermit não somente a iluminação de sua própria processualidade estrutural que tentamos descrever, mas, nessa própria processualidade, uma alternativa à história do idealismo alemão finalizada por Hegel, e o equivalente de uma escalada do idealismo subjetivo rumo ao idealismo absoluto, equi- 
valente cujos momentos seriam as duas primeiras Críticas e o coroamento final, a Terceira. Mas se Vuillemin pode apontar a magistral lição de leitura interna dada pela interpretação de Guillermit, lição que vale inclusive retroativamente para os grandes leitores especulativos de Kant, isso ocorre porque "nenhum deles soubera ler Kant até o fim, nem encontrara as extensões e purificações sucessivas e, portanto, as re novações da revolução copernicana que o próprio Kant havia introduzido em virtude da elucidação crítica" (VUILLEMIN, 1977, p.VI). O alcance dessa interp retação para a justificação do idealismo radical aplicado ao caso da história do idealismo alemão é menos claro.

Não há dúvida de que o Vuillemin de 1984 saudou na obra do amigo desaparecido ${ }^{23}$, com penetração e emoção singulares, uma espécie de autêntico avatar, uma espécie de destino não transformado em fatalidade, da revolução copernicana, de que o Vuillemin de 1954 havia descrito a infeliz herança kantiana. Mas o mesmo Vuillemin de 1984 não deixava de chamar atenção para um ponto necessariamente deixado em suspenso pelo inacabamento da obra de Guillermit, e que gostaríamos de evocar para finalizar naquilo que nos parece abrir para duas questões ligadas, e que nos parecem indecididas, tanto no interior do método das estruturas aplicado a Kant, quanto no princípio do idealismo radical.

De um lado, quanto ao problema da libertação dos constrangimentos acessórios que as condições do conhecimento sensível fazem incidir sobre o sistema do idealismo transcendental - libertação que exige o restabelecimento dos direitos do supra-sensível mesmo num ser racional afetado sensivelmente -, Kant compreendeu que era preciso dar ele mesmo uma solução, identificando na Razão prática, e não no Juízo, a chave da abóboda de seu sistema. Com efeito, essa subordinação do entendimento à Razão se opera mesmo na Terceira Crítica, e nela talvez ainda de maneira mais acabada. Vuillemin nota vários dos pontos estratégicos dessa articulação interna ao sistema kantiano, tal como é apreendida pela elucidação crítica: dife rença entre Analítica do Belo e Analítica do Sublime (se o que está em jogo é o repouso ou o movimento da mente, da qual se diz que a Razão é única força propriamente motora, "Die eigentliche bewegende Kraft", assim como a Lei ou a liberdade como Lei é dita causa motora, Bewegursache, que nos faz sentir a sublimidade de nossa própria existência supra-sensível) ${ }^{24}$, mas também diferença 
entre as duas espécies do sublime, o matemático e o dinâmico, cujo movimento reconduz a imaginação a operar em sua relação com a faculdade de conhecer ou com a faculdade de desejar na unidade de uma só Razão. Seria preciso acrescentar a distinção entre a realização inicial da Dedução do Belo no Beziehungspunkt universal das faculdades sensitiva e intelectual (KdU, $\ 9$ ), ponto de referência exigido pela explicação do prazer do juízo estético provocado pela reflexão sobre o estado da mente, e sua realização final no Vereinigungspunkt, ponto de convergência de todas nossas faculdades a priori no supra-sensível. ${ }^{25} \mathrm{Se}$, sem dúvida, a elucidação crítica tem como atuar na processualidade objetivada da estruturação do sistema kantiano, sua atuação seria no entanto de tal ordem que seria necessário inverter o juízo kantiano, não sobre a estrutura, mas sobre o conteúdo subjetivo, não objetivado, do sistema em seu primado prático? Vuillemin, sem dúvida, não o pensava, nem tampouco Louis Guillermit, já que para comentar esse papel de primeiro motor atribuído por Kant à Razão ele remete aos textos citados por Guillermit em que esse primado é conservado, e fortalecido, no interior da Crítica do Juízo, por um espírito capaz, e o único a ser capaz, de ser princípio de vida, de vida no sentido de uma atividade interna que não é atividade senão do pensamento, e de um pensamento do qual todas as forças vivas só podem ser determinadas pela Razão. ${ }^{26} \mathrm{O}$ capítulo sobre a Analítica do Sublime se acabava justamente com a evocação desse papel de "autêntico primeiro motor" da Razão. Em tais condições, como atribuir unicamente à elucidação crítica da Crítica do Juizo o poder de iluminar, mediante a descoberta de uma chave da abóboda comandada por um sujeito que "ousou se libertar dos apoios externos e dos contrafortes do objeto e do desejo", uma segunda revolução copernicana, que seria "a forma do incondicional e do absoluto próprio à filosofia de Kant"? Em suma, como obter a transmutação de uma estrutura do absoluto em absoluto subjetivo? E isso não teria de ser feito, imperativamente, nos termos mesmos da exaltação final da Razão na última Crítica? Concluamos esse primeiro ponto com Vuillemin: "A redação de Louis Guillermit se detém no ponto supremo a que a elucidação pode pretender se alçar, ela se detém nessa força motriz da razão que, no plano da filosofia transcendental, só pode ser comparada ao pensamento do pensamento, tal como posto por Aristóteles no livro $\$ da Metafísica." (VUILLEMIN, 1986, pp. 
VII-VIII). Sem prejulgar que esclarecimento final Guillermit poderia ter dado à forma kantiana do idealismo sistemático, não temos pelo menos o direito de duvidar que o método das estruturas pode dar conta das razões que levam esse idealismo a não ultrapassar a prudência crítica na satisfação dos interesses tanto práticos quanto teóricos de uma Razão, a qual, no entanto, é a única causa motora das faculdades da mente? E, nesse caso, o método das estruturas não ativaria, quanto à inteligibilidade mesma do sistema, uma espécie de explicação que levaria inevitavelmente a pôr a limpo as razões, elas mesmas não estruturais, da preferência de Gueroult pelo idealismo radical, que faz a escolha de Kant contra Hegel no princípio do método?

Por outro lado, com efeito, a substituição de um absoluto substancial por um absoluto estrutural autônomo nos reconduz, para terminar, à questão de saber se esse idealismo radical é conseqüente consigo mesmo, ainda que esse absoluto seja conhecível para Kant apenas praticamente, e não na teoria, como absoluto visado pela Razão, faculdade de princípios e do incondicionado, cuja origem é o supra-sensível. Sem a posição de um absoluto substancial $e$ subjetivo, mas também substancial, é permitido certamente pensar uma multiplicidade de sistemas absolutos em suas ordens, eVuillemin não deixa de abrir sua Introdução ao Kant de Guillermit lembrando os arrependimentos que Gueroult devia acrescentar, em nome da autonomia das estruturas, a seu primeiro juízo hegeliano sobre Fichte (VUILLEMIN, 1986, pp. I-II). Mas não se corre assim o risco de tornar racionalmente incompreensível aquilo que pode por vezes motivar a arquitetônica de um sistema a extrapolar seus próprios limites, não simplesmente do interior, como na construção escalonada das Estéticas kantianas, mas precisamente sob o efeito de uma intenção ou pressuposição ao mesmo tempo motora e contrariada? Em suma, a teleologia da história não nos leva a perder a efetividade concreta? E, no caso de Kant, por objetivar demasiadamente a forma daquilo que faz as vezes de absoluto para ele, não se corre o risco não somente de reduzir sua dimensão subjetiva, mas de fazer de sua própria escolha em matéria de absoluto (é sem dúvida totalmente coerente manter a este numa altura diferente da do absoluto dos sucessores dele) uma espécie de ponto cego ou de questão de gosto pessoal dos filósofos, quando o que está em jogo, tanto ou mais que na escolha da estrutura, é esta decisão liv re com a qual o 
idealismo radical pretende acreditar, mas como que a fundo perdido, a liberdade de toda experiência filosófica? Se essas experiências filosóficas são mesmo absolutos de racionalidade, mas absolutos plurais em última análise, e se por isso cada uma delas é para sempre muda sobre o pensamento que ela sabe conter e sobre aquilo que ela sabe escolher ou herdar, bem como sobre o horizonte de necessidade absoluta que ela admite no princípio da racionalidade de suas livres escolhas, então decididamente não é seguro que o idealismo gueroultiano não tenha com efeito " radicalizado" alguns de seus traços, como o racionalismo anistórico ou o abandono irracional a seus inúmeros pressupostos filosóficos, dos quais ele pretendia no entanto purificar o idealismo de Hegel em geral, mas particularmente e significativamente o idealismo de Hegel leitor da forma kantiana de um sistema de idealismo subjetivo para a razão pura.

1 O presente texto é o da comunicação apresentada durante o Colóquio Franco-Brasileiro, organizado por L. Jaffro e M. Suzuki em Clermont-Ferrand, nos dias 27 a 29 de setembro de 2006. O tema do colóquio "Estrutura, sistema e subjetividade", foi proposto pelos amigos brasileiros.

2 GUILLERMIT, 1977. Nessa homenagem póstuma ao historiador, L. Guillermit redigiu a parte consagrada a Kant, enquanto J.Vuillemin ficou responsável pelo conjunto e por aquilo que dizia respeito a Fichte; G. D reyfus se ocupou de Descartes e dos cartesianos, eV. Goldschmidt, da Dianoemática.

${ }^{3}$ GUEROULT, 1930. Nessa concepção do devir do idealismo alemão, a tese de M. Gueroult concorda com a que seria mais tarde desenvolvida por B. Bourgeois e explicitada em sua obra recente BOURGEOIS, 2000.

${ }^{4}$ Não se deve esquecer que a tese de de Gueroult é dedicada a Léon Brunschwicg.

5 GUEROULT, 1984-1988. A História da história da filosofia, em três volumes, é publicada por seu editor, Ginette Dreyfus, como o livro I da Dianoemática Filosofia da história da filosofia, que constitui o livro I, veio à luz em 1979; o conjunto foi publicado pela editora Aubier, de Paris.

6 No número da revista Archiv für Geschidte der Philosophie, citado acima, nota 2, as contribuições de Guillermit et de Goldschmidt remetem especificamente a uma nota do estudo crítico de uma obra de Souriau publicada em 1952 (SOURIAU, 1952, p. 95); aos dois textos, de 1956 e 1965, publicados em Roma e Milão: "Le problème de la légitimité de l'histoire de la philosophie" e "La discorde de la philosophie avec son passé"; a um inédito, "L'essence de l'histoire de la philosophie" e, finalmente, à "Leçon Inaugurale au Collège de France" (4 de dezembro de 1951), que legitimam, a partir dessa última data, a "tecnologia dos sistemas" como método da história da filosofia assimilada a uma filosofia.

doispontos, Curitiba, São Carlos, vol. 5, n. 1, p.11-42, abril, 2008 
7 Guillermit visa aqui a continuação imediata do texto da Crítica da razão pura.

${ }^{8}$ Citamos a partir da tradução de Guillermit, inserida como epígrafe da primeira parte "L'invention critique de l'esthétique" de sua obra póstuma (GUILLERMIT, 1986, p. 13).

${ }^{9}$ No início da Lógica Transcendental, Kant diz que a unidade qualitativa do conceito, por comparação com a "unidade do conjunto da diversidade dos conhecimentos", é mais ou menos como a unidade do tema num drama, num discurso, numa fábula ("wie etwa die Einheit des Themas in einem Schauspiel, einer Rede, einer Fabel” (KrV, B 114).

10 Kant cita o verso latino "nil actum reputans si quid superesset agendum".

${ }^{11}$ A tradução francesa de Tremesaygues-Pacaud, p. 560, tem uma gralha: "manque" aparece no lugar de "masque".

12 LEBRUN, 1970. Louis Guillermit se rejubilava de seu acordo textual com Lebrun, e seus amigos de Aix-en-Provence podem testemunhar que, finalizando naquela época sua própria tese principal, ele declarava, quando a obra de Lebrun foi lançada, que podia jogar no lixo alguns capítulos que haviam se tornado inúteis, tendo em vista que suas análises haviam sido precedidas exatamente como tais por Lebrun. É bastante surpreendente que, nas publicações em que saudaram o bicentenário da Crítica, Guillermit tenha desta vez precedido as análises de seu amigo. Dedicamos um estudo a essa comparação, exposto em agosto de 2007 na Universidade de São Paulo, a convite de M. Suzuki, graças a quem o texto deverá ser futuramente publicado no Brasil.

${ }^{13}$ Tomamos essa comparação no sentido preciso que lhe é dado por Kant no célebre $₫ 27$ da Dedução transcendental das categorias.

${ }^{14}$ Citamos aqui a tradução do texto por Guillermit (GUILLERMIT, 1986, pp. 9-10), e no artigo "Esthétique et critique" (GUILLERMIT, 1976)

15 Que nos seja permitido citar esse texto em detalhe, pois, por sua densidade, ele resiste, tanto quanto o de Vuillemin, a qualquer resumo ou evocação discursiva.

16 O caráter duplo, positivo e dedutivo (no sentido transcendental do termo) é reafirmado e sintetizado à p. 224.

17 Gueroult estabelece uma combinatória de quatro atitudes possíveis quanto ao valor da ciência e da metafísica, e ele opõe sua dupla resposta positiva à resposta mista de Kant.

18 Esse livre postulado, restaurador de um realismo das Idéias que o intuicionismo mutilou, se encontra, acreditamos, posto no princípio das correções que Jules Vuillemin propôs para o kantismo e, posteriomente, no princípio de sua classificação dos sistemas da filosofia, naquilo que ela oferece talvez de alternativa à Dianoemática, e, finalmente, no princípio do "a rigo de fé" num mundo inteligível que está no centro de seu ultimíssimo texto, o de sua conferência de 25 de março de 2000 na Sociedade Francesa de Filosofia. Ele pretende mesmo, talvez mais nitidamente que Gueroult, permanecer em Fichte ou completá-lo com Platão, mas aquém de Hegel.

19 É sobre esse círculo que medita o $\ 47$ da Dianoemática, GUEROULT, 1984-1988, p. 193.

20 BOURGEOIS, 2001, p. 192. O texto de Gueroult não é citado. Trata-se, bem entendido, do capítulo XXII do volume 2 de GUEROULT, 1984-1988 Mas nesse capítulo Guero ult

doispontos, Curitiba, São Carlos, vol. 5, n. 1, p.11-42, abril, 2008 
expõe as duas concepções, a de juventude e a de maturidade, sugerindo menos uma oposição que um deslizamento entre uma e outra. No entanto, sente-se um evidente apego à primeira concepção, e tanto Bernard Bourgeois quanto Victor Goldschmidt indicam em que sentido profundo a Dianoemática se decidira por ela, nela vendo uma alternativa à segunda, que importará a Gueroult inverter.

${ }^{21}$ Em dive rsas ocasiões, tentamos comentar esse ponto. Permitimo-nos a remissão, por exe mplo, a SCHWARTZ, 2005.

${ }^{22}$ VUILLEMIN, 1977, p. 292.Vuillemin cita o primeiro volume da tese (GUEROULT, 1930, p. 269). Mas também cita o segundo volume (GUEROULT, 1930, pp. 227-235), caracterizando as analogias do desenvolvimento da Doutrina-da-Ciência com a Fenomenologia de Hegel.

23 O texto da introdução à obra póstuma de 1986 é retomada do texto da conferência proferida em 1984 na Universidade de Aix, durante uma jornada de homenagem dois anos após o desaparecimento de Louis Guillermit, jornada cujas comunicações foram pulicadas num In Memoriam nas Presses Universitaires de Provence, 1986.

${ }^{24}$ VUILLEMIN, 1977, Introdução, pp.VII-VIII; a remissão é ao texto de GUILLLERMIT, capítulo IV, em particular, a esse respeito, pp. 150-152.

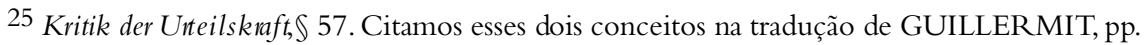
197 e 286. O autor os comenta às pp. 157-160.

${ }^{26}$ VUILLEMIN, 1977, p.VII. Ele remete à página 152 do liv ro de Guillermit: poderíamos remontar ao menos até a página 137 e à explicação da distinção das duas espécies de sublime feita sob os auspícios da distinção entre repouso e movimento da mente. É a propósito dessas sínteses dinâmicas, cuja exposição se articula perfeitamente com a exposição dos dois tipos de sínteses dos Princípios feita por Vuillemin em Physique et Métaphysique Kantienne, que Guillermit mobiliza vários textos de Kant, em primeiro lugar os da Crítica da Razão Prática, cuja temática não apenas permanece, mas até culmina na Crítica do Juízo, no momento de apreender na Razão a única faculdade automotora, no sentido em que apenas a mente "é nela mesma inteiramente vida, princípio de vida" (Kritik der Urteilskraft, $\mathbb{\$} 29$, Observação geral; tradução de Guillermit, p. 241).

\section{Referências bibliográficas}

BOURGEOIS, B. 2000. L'Idéalisme allemand. Alternatives et progrès. Paris: Vrin.

.2001. "L'invention philosophique: de l'idéalisme absolu de Hegel à l'idéalisme radical de Gueroult". In: Comment écrire l'histoire de la philosophie?. Edição de Y.C.Zarka. Paris: P.U.F. 
COHEN, H. 1918 Kants Theorie der Erfahrung. Tradução francesa de Dufour e Servois. Paris, Cerf, 2001.

GUEROULT, M. 1930. L'Évolution et la structure de la doctrine de la science chez Fichte. Paris: Les Belles Lettres.

. 1931. "Le jugement de Hegel sur l'antithétique de la raison pure". In: Revue de Métaphysique et de Morale, n. 3, PP. 413-439.

. 1954. "Le Canon de la raison pure et la Critique de la raison pratique". In: Revue Internationale de Philosophie.

. 1971. “Les 'déplacements' de la conscience morale kantienne selon Hegel. In: Hommage à Jean Hyppolite. Paris: Puf. .1984-1988. Histoire de l'histoire de la philosophie. Paris: Aubier.

GOLDSCHMIDT,V. 1953. Le système stö̈cien et l'idée du temps. Paris:Vrin. . 1977. "La Dianoématique", Archiv für die Geschichte der Philosophie, vol. 59, tomo 3, pp. 304-312. 1982. Temps physique et temps tragique chez Aristote. Paris:Vrin.

GRANGER, G.G. 1967. “Au lecteur, sur les structuralismes”. In: Pensée formelle et sciences de l'homme. Paris: Aubier, 1967, pp. 1-6.

GUILLERMIT, L. 1976. "Esthétique et Critique”. In: Sinnlichkeit und Verstand in der deutschen und französischen Philosophie von Descartes bis Hegel. Edição de H. Wagner. Bonn: Bouvier.

. 1977. "Kant". In: Archiv für die Geschichte der Philosophie, vol. 59, tomo 3, pp. 301-304.

. 1986. L'élucidation critique du jugement de goût selon Kant. Paris: CNRS.

HUSSERL, E.1969. Logische Untersuchungen.Tradução francesa, Paris: Puf. LEBRUN, G. 1970. Kant et la fin de la métaphysique. Paris: Armand Colin. LEVY-STRAUSS, C. 1964. Mythologiques. Le cru et Le cuit. Paris: Plon. 
RICOEUR, P. 1963. "Symbole et temporalité". In: Archivio di Filosofia, n. 1-2.

SCHWARTZ, E. 2005. "Histoire des mathématiques et histoire de la philosophie chez J.Vuillemin.”. In: Philosophie des mathématiques et théorie de la connaissance. L'oeuvre de J. Vuillemin. Edição de R. Rashed e P. Pellegrin. Paris: Blanchard.

SOURIAU, E. 1952. Mélanges d'esthétique et de science de l'art : offerts à Étienne Souriau, professeur à la Sorbonne. Paris: Nizet.

VUILLEMIN, J. 1955. Physique et métaphysique kantiennes. Paris: PUF. . 1977. "Apresentação" ao número em homenagem a Martial Gueroult. Archiv für die Geschichte der Philosophie, vol. 59, tomo 3. 1977b. "Fichte", Archiv für die Geschichte der Philosophie, vol. 59, tomo 3, pp. 289-293. 